\title{
Evaluation of Image Noise and Radiation Dose Analysis In Brain CT Using ASIR(Adaptive Statistical Iterative Reconstruction)
}

\author{
HyonChol Jang*, KyeongKeun Kim*, Jaehwan Cho**, Jeongmin Seo ${ }^{* * *}$, HaengKi Lee* \\ Department of Radiotechnology, Suseong College*, \\ Department of International Radiological Science, Hallym University of Graduate Studies ${ }^{* *}$, \\ Department of Radiological Science, Daewon University College ${ }^{* * *}$
}

\section{ASIR를 이용한 두부 CT의 영상 잡음 평가 및 피폭선량 분석}

\author{
장현철*, 김경근 ${ }^{*}$, 조재환**, 서정민 ${ }^{* * *}$, 이행기 \\ 수성대학교 방사선과*, 한림국제대학원대학교 국제방사선학과**, 대원대학교 방사선과***
}

\begin{abstract}
The purpose of this study on head computed tomography scan corporate reorganization adaptive iteration algorithm using the statistical noise, and quality assessment, reduction of dose was evaluated. Head CT examinations do not apply ASIR group [A group], ASIR 50 applies a group [B group] were divided into examinations. B group of each $46.9 \%, 48.2 \%, 43.2 \%$, and $47.9 \%$ the measured in the phantom research result of measurement of $\mathrm{CT}$ noise average were reduced more than A group in the central part (A) and peripheral unit (B, C, D). CT number was measured with the quantitive analytical method in the display-image quality evaluation and about noise was analyze. There was A group and difference which the image noise notes statistically between B. And A group was high so that the image noise could note than B group (31.87 HUs, 31.78 HUs, 26.6 HUs, 30.42 HU P<0.05). The score of the observer 1 of A group evaluated 73.17 on 74.2 at the result 80 half tone dot of evaluating by the qualitative evaluation method of the image by the bean curd clinical image evaluation table. And the score of the observer 1 of B group evaluated 71.77 on 72.47. There was no difference $(\mathrm{P}>0.05)$ noted statistically. And the inappropriate image was shown to the diagnosis. As to the exposure dose, by examination by applying ASIR $50 \%$ there was no decline in quality of the image, 47.6 $\%$ could reduce the radiation dose. In conclusion, if ASIR is applied to the clinical part, it is considered with the dose written much more that examination is possible. And when examination, it is considered that it becomes the positive factor when the examiner determines.
\end{abstract}

Key words : Lowdose, Noise, Computed Tomography

\section{요 야}

본 연구는 두부 컴퓨터 단층 촬영 검사 시 적응식 통계적 반복 재구성법인 알고리즘을 적용하여 노이즈 및 화질평 가, 피폭선량의 감소에 대하여 알아보고자 하였다. 두부 CT 검사 시 ASIR를 적용하지 않은 군[A군], ASIR $50 \%$ 적 용한군 [B군]으로 나누어 검사하였다. 팬텀연구에서 측정된 $\mathrm{CT}$ 노이즈 평균값의 측정결과는 $\mathrm{B}$ 군이 $\mathrm{A}$ 군보다 중심부 
(A)와 주변부(B, C, D)에서 각 각 $46.9 \%, 48.2 \%, 43.2 \%, 47.9 \%$ 가 감소되었다. 영상화질 평가에서 정량적 분석 방법으로 $\mathrm{CT}$ 값(number)을 측정하여 잡음(noise) 정도를 분석하였다. 영상 잡음은 $\mathrm{A}$ 군과 $\mathrm{B}$ 군 사이에는 통계적으로 유의한 차이가 있었으며, A군이 B군보다 영상 잡음이 유의하게 높았다(group A ;우엽에서 $31.87 \mathrm{HU}$, 좌엽에서 31.78 $\mathrm{HU}$, group B ; 우엽에서 $26.6 \mathrm{HU}$, 좌엽에서 $30.42 \mathrm{HU}: \mathrm{P}<0.05$ ). 영상의 정성적 평가방법으로 두부 임상 영상 평가 표에 의해 평가한 결과 80 점 만점에 $\mathrm{A}$ 군의 관찰자 1 의 점수는 73.17 점, 관찰자 2 의 점수는 74.2 점으로 평가하였으 며, $\mathrm{B}$ 군의 관찰자 1 의 점수는 71.77 점, 관찰자 2 의 점수는 72.47 점으로 평가하였다. 통계적으로 유의한 차이가 없었 으며 $(\mathrm{P}>0.05)$, 진단에 적절한 영상을 보였다. 피폭선량은 ASIR $50 \%$ 적용하여 검사함으로써 영상의 질적 저하 없이 방사선 피폭선량을 $47.6 \%$ 감소 시킬수 있었다. 결론적으로 임상 부위에 ASIR가 적용이 된다면 훨씬 더 적은 선량으 로도 검사가 가능할 것으로 사료되며, 검사 시에 검사자가 판단하는데 있어 긍정적인 요인이 될 것으로 사료된다.

중심단어: 저선량, 노이즈, 컴퓨터단층촬영

\section{I. 서론}

영상의학과에 검사에 있어서 컴퓨터 단층 촬영 (Computed tomography. CT)은 우수한 진단 영상을 제 공하고 있다. 국민들의 수명이 늘어남에 따라 건강에 대한 관심이 많아지면서 건강 검진을 목적으로 하는 CT 검사 횟수가 증가하는 추세이다.

검사 횟수의 증가로 인해 방사선에 의한 노출 위 험이 증가하였으며, 더욱이 반복 검사를 하는 환자들 에게 있어서는 방사선 노출이 더 높을 수 밖에 없는 실정이다 ${ }^{[1]}$. CT 검사는 일반 X-선 검사 보다 방사선 피폭이 많은 것으로 보고 되었으며 ${ }^{[2]}$, 이로 인해 환자 들이 방사선 피폭선량에 대해 더욱더 많은 관심을 가 지고 있다.

CT 검사로 인한 방사선 노출을 줄이기 위하여 장비 회사 마다 피폭을 줄이면서 진단에 적합한 화질을 얻 기 위하여 노력하고 있으며, 여러 방법들이 현재 다중 검출기 컴퓨터 단층 촬영(Multi-detector Computed tomography. MDCT)을 통하여 이용되고 있다.

피폭을 줄이기 위한 방법으로 영상의 노이즈를 일 정하게 유지시키기 위해 관전류가 자동적으로 조절이 되어지는 자동노출조절(Automatic exposure control. A $\mathrm{EC}$ ) 적용, 여과 필터 사용, 검사 부위의 목적에 따른 저선량 프로토콜(Protocol) 등이 적용 되고 있다 ${ }^{[3-4]}$.

최근에 $\mathrm{CT}$ 영상의 질적 저하 없이 선량을 감소 시 키는 재구성 알고리즘인 적응식 통계적 반복 재구성

법(Adptive statistical iterative reconstruction. ASIR)이 소
개 되었다 ${ }^{[5]}$. CT 검사에 있어서 일반인이 받는 방사선 피폭선량이 약 $67 \%$ 정도 이며, 총 CT 검사중의 $45 \%$ 가 두부 CT 검사라고 보고 되고 있다 ${ }^{[6-7]}$.

따라서 본 연구에서는 최근에 소개된 ASIR를 적용 하여 두부 검사 시 노이즈 및 화질 평가, 피폭선량의 감약 정도를 분석하여 ASIR 사용의 유용성을 평가하 고자 한다.

\section{II. 대상 및 방법}

\section{1. 팬텀 연구}

\section{1 장비 및 측정 조건}

CT 장비는 64 MDCT (LightSpeed VCT XTe, GE Healthcare, Milwaukee, USA)을 이용하였다.

노이즈 평가를 위해 사용된 팬텀은 미국 의학 물리 학회(American Association of Physicists in Medicine.AA $\mathrm{PM}$ )에서 고안된 CT 성능 평가용 팬텀(model 76-410, Nuclear Associates LTD, Carle Place, N.Y, USA)을 사용 하였다.

\section{2 노이즈 측정}

본 연구에서 노이즈 측정은 $\mathrm{AAPM}$ 팬텀을 이용하여 CT 장비의 테이블에 고정 시킨 후 레이저 빔을 이용 하여 X-ray가 조사되는 중심점에 위치 시킨 후, 관전압 $120 \mathrm{kVp}$ 에 $250 \mathrm{~mA}$ 의 조건으로 ASIR 적용하지 않은 A 
군과, ASIR $50 \%$ 적용한 B군으로 나누어 스캔하였다. 팬텀 영상에 관심영역(Region of interest. ROI)을 $4 \mathrm{~cm}$ $\mathrm{X} 4 \mathrm{~cm}$ 로 하였으며, 면적은 $1585 \mathrm{~mm}^{2}$ 로 고정하였다. 중심부(6시 방향을 기준으로 $1 / 4$ 저점. A점)와 주변부 9시(B점), 12시(C점), 3시(D점)에 위치를 고정 한 후 모 니터에 표시된 $\mathrm{CT}$ 노이즈 값을 기록하였다 $(\mathrm{B}, \mathrm{C}, \mathrm{D}$ 점 의 관심영역은 $2 / 3$ 지점에 두고 측정해야 하며, 관심 영역의 면적은 $1,580 \sim 1,620 \mathrm{~mm}^{2}$ 사이에 있어야 한 다) ${ }^{[8]}$.

$\mathrm{CT}$ 노이즈 값을 각 3 회씩 측정하여 평균값을 기록 하였다[Fig. 1].

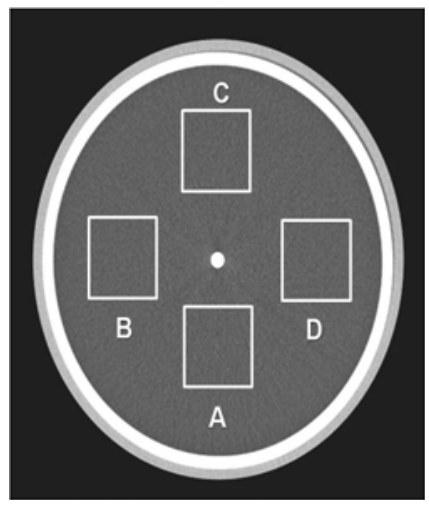

Figure 1. Measurement of CT noise with Phantom study

\section{2. 임상 연구}

\section{1 검사 대상}

2011년 12월부터 2012년 2월까지 S병원에서 건강 검 진을 목적으로 두부CT 검사를 위해 내원한 60 명의 성 인을 대상으로 동의하에 연구를 하였다. 연령분포는 35세부터 74세 였다[Table 1].

Table 1. Characteristics of Patients by Groups

\begin{tabular}{ccc}
\hline & Group A & Group B \\
\cline { 2 - 3 } Characteristics & Non - ASIR & $50 \%$ ASIR \\
& $(n=30)$ & $(n=30)$ \\
\hline No. of M / F & $15 / 15$ & $18 / 12$ \\
Age (year) & 53.9 & 50.5 \\
\hline
\end{tabular}

* M: male, F : female

\section{2 검사 방법}

본 연구에서 이용한 ASIR 알고리즘은 소프트웨어 프로그램 개발로 인해 통계적으로 영상을 반복 재구 성하여 기존의재구성법인 역투영법(Filterd back projection. FBP)과 적절하게 조합되어 기존의 선량보다 더 적은 선량으로도 영상의 질적 저하 없이 나타내는 재구성법이다 ${ }^{[5]}$.

사용한 장비는64-MDCT(LightSpe ed VCT XTe, GE Healthcare, Milwaukee, USA)를 이용하였고, 두부 CT 검 사 시 이용된 파라메터는 $20 \mathrm{~mm}$ detector coverage, Rotation time $1 \mathrm{sec}$, 관전압 $120 \mathrm{kVp}$, 관전류 $250 \mathrm{~mA}$ 조 건으로 설정하였다. 검사 범위를 두부 전체가 포함되 도록 두개 저부(Skull base)에서 마루점(Skull vertex)까지 하였다. 팬텀 연구와 동일한 방법으로 2 개의 군으로 분류하여 검사 하였다[표 1].

\section{3 영상 화질 평가}

정량적 분석 방법으로 CT 값(number)을 측정하여 잡음(noise) 정도를 분석하였다.

$5 \mathrm{~mm}$ 슬라이스 두께로 검사한 전체 영상 중 가운 데 영상을 택하여 뇌의 좌엽(left lobe)과 우엽(right lobe) 중심부에 $30 \mathrm{~mm}^{2}$ 의 관심영역(ROI)을 설정 한 후, CT 값(number)을 측정하여 평균값과 표준편차를 분석 하였다[Fig. 2].

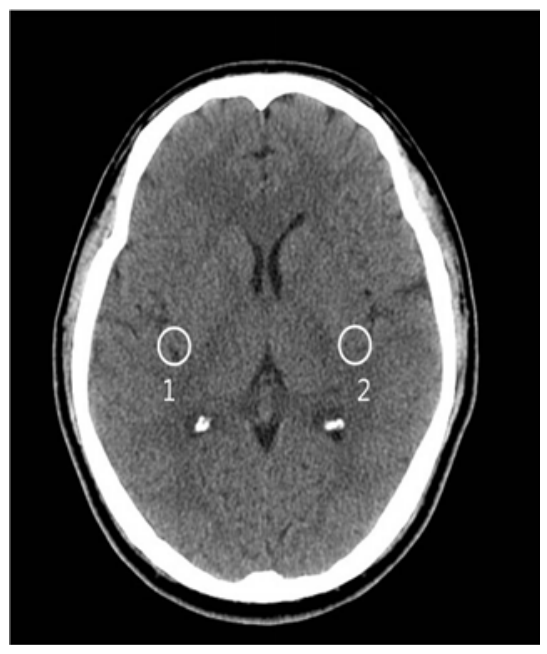

Figure 2. The region of interest location 
관심영역의 $\mathrm{CT}$ 값의 평균값은 대응표본검정(Paired T-test, SPSS win 18.0)을 이용하였으며, P값이 0.05 이하 일 때 통계적으로 유의한 차이가 있는 것으로 간주하 였다.

\section{4 임상 영상 평가표에 의한 평가}

정성적 분석 방법으로 $\mathrm{CT}$ 의 임상 영상 검사에서 두 부 부위에 실제적으로 적용하여 평가하는 두부 임상 영상 평가표를 이용하였으며, 영상 정보 항목별로 인 공물 부분, 포함범위 부분, 해상도 및 대조도 부분, 영 상창의 적정성 부분, 절편 두께의 적정성 부분으로 분 석하였다. 영상의학과 신경영상의학 전문의 1 명과 영 상의학과 전공의 1 명이 분석하였다.

임상 영상 평가표에 의한 총점 100 점 만점에 일반 정보 항목 20 점을 배제한 80 점 만점으로 평가하였으 며, 정확도를 위해 동일한 판독용 모니터를 이용하여 분석하였고, 논문과 관련된 내용은 암시하지 않았다 [Table 2].

통계방법으로는 대응표본검정(Wilcoxon, SPSS win 18.0)을 이용하였으며, P값이 0.05 이하일 때 통계적으 로 유의한 차이가 있는 것으로 간주하였다.

Table 2. The clinical image evaluation table

\begin{tabular}{|c|c|c|c|}
\hline \multicolumn{4}{|c|}{ 임상영상평가표 (두부) } \\
\hline 항목 & 평 가 내 용 & 기준점수 & 점수 \\
\hline \multicolumn{4}{|c|}{ 영상 정보 항목 } \\
\hline 인공물 & $\begin{array}{l}\text { 1.환자의 움직임에 의한 인공물이 없다. } \\
\text { 2.Beam-hardening artifact가 없다. } \\
\text { 3.Ring artifact 가 없다. } \\
\text { 4.그 외의 인공물이 없다. }\end{array}$ & 각3점 & \\
\hline 포함범위 & $\begin{array}{l}\text { 1.두정부에서 두개골 부까지 포함한다. } \\
\text { 2.두개골 전폭이 포함 되었다. } \\
\text { 3.0rbitomeatal I ine 에 맞추어 } \\
\text { tilting 되었다. } \\
\text { 4.좌우가 대칭적으로 촬영 되었다. }\end{array}$ & 각 4점 & \\
\hline $\begin{array}{l}\text { 해상도 } \\
\text { 및 } \\
\text { 대조도 }\end{array}$ & $\begin{array}{l}\text { 1.회백질과 백질의 구분이 가능하다. } \\
\text { 2.기저핵이 구분된다. } \\
\text { 3.Sylvian fissure 가 구별된다. } \\
\text { 4.뇌고랑이 식별된다. } \\
\text { 5.중대뇌동맥의 근위부가 식별된다. } \\
\text { 6.소뇌 충부(vermis) 가 식별된다. } \\
\text { 7.Cerebel lopont ine cistern 이 } \\
\text { 식별된다. } \\
\text { 8.소뇌의 피질과 심부백질의 구분이 } \\
\text { 가능하다. }\end{array}$ & 각5점 & \\
\hline
\end{tabular}

\begin{tabular}{|c|c|c|c|}
\hline $\begin{array}{c}\text { 영상창의 } \\
\text { 적 정 성성정과 골격설정이 별도로 }\end{array}$ & 4점화되었다. & \\
\hline $\begin{array}{c}\text { 절편두께 } \\
\text { 의 }\end{array}$ & $\begin{array}{c}\text { 1.절편두)께가 천막상부에서 } 8 \mathrm{~mm} \\
\text { 이하, 후두개와에서는 } 5 \mathrm{~mm} \text { 이하이다. }\end{array}$ & 각4점 & \\
$\begin{array}{c}\text { 적 정 성 } \\
\text { 2.절편간격이 없어야 한다. }\end{array}$ & & \\
\hline \multicolumn{2}{|c|}{ 영상정보항목 점수 } & 80점 & \\
\hline
\end{tabular}

\section{5 피폭선량 분석}

피폭 선량의 측정은 ASIR 적용하지 않은 A군과 ASI $\mathrm{R} 50 \%$ 적용한 B군을 이용하여 장치에서 자동 계산되 어지는 CTDIvol 을 기록하여 분석하였다.

피폭선량 분석 통계방법으로는 대응표본검정(Paired T-test, SPSS win 18.0)을 이용하였으며, P값이 0.05 이하 일 때 통계적으로 유의한 차이가 있는 것으로 간주하 였다.

CTDIvol 촬영 축에서의 CTDI로 Z축에서 노출 변동 을 감안한 값으로 구하는 식은 다음과 같다 ${ }^{[8-11]}$.

CTDIvol $=$ CTDIw X NT $/ \mathrm{I}$ [식 1]

CTDIvol $=$ CTDIw $/$ Pitch $\cdot[$ 식 2]

I : 나선형 CT의 Rotation당 테이블 이동거리

NT : 영상을 얻는 동안 전체 빔의 두께

CTDIw : 가중 CT 선량지수

Pitch : X선관이 회전하는 1회전하는 동안 테이블 이동거리

III. 결과

\section{1. 노이즈 분석}

ASIR 적용하지 않은 A군과 ASIR $50 \%$ 적용한 B군 으로 나누어 팬텀에서 3 회씩 측정된 $\mathrm{CT}$ 노이즈 평균 값의 측정결과는 $\mathrm{A}$ 군에서 중심부 $(\mathrm{A})$ 와 주변부 $(\mathrm{B}, \mathrm{C}$, $\mathrm{D}$ )에서 각 각 $6.28 \mathrm{HU}, 5.77 \mathrm{HU}, 5.93 \mathrm{HU}, 5.72 \mathrm{HU}$ 로 측정되었으며, $\mathrm{B}$ 군에서 중심부 $(\mathrm{A})$ 와 주변부 $(\mathrm{B}, \mathrm{C}, \mathrm{D})$ 에 는 각 각 $3.33 \mathrm{HU}, 2.99 \mathrm{HU}, 3.37 \mathrm{HU}, 2.98 \mathrm{HU}$ 로 측정 되었다[Table 3][Fig. 3].

$\mathrm{A}$ 군과 $\mathrm{B}$ 군을 비교해 본 결과 $\mathrm{B}$ 군이 $\mathrm{A}$ 군보다 중심 부(A)와 주변부(B, C, D)에서 각 각 $46.9 \%, 48.2 \%$, 
$43.2 \%, 47.9 \%$ 가 감소되었다.

Table 3. Analysis of the Phantom noise by Groups

\begin{tabular}{cccccccccc}
\hline & \multicolumn{4}{c}{ Group A } & \multicolumn{5}{c}{ Group B } \\
\cline { 2 - 10 } No. & A & B & C & D & A & B & C & D \\
\hline 1 & 6.29 & 5.77 & 5.91 & 5.71 & 3.32 & 2.99 & 3.37 & 2.98 \\
2 & 6.28 & 5.75 & 5.94 & 5.73 & 3.33 & 3 & 3.38 & 2.99 \\
3 & 6.26 & 5.78 & 5.93 & 5.72 & 3.33 & 2.98 & 3.36 & 2.98 \\
\hline & 6.28 & 5.77 & 5.93 & 5.72 & 3.33 & 2.99 & 3.37 & 2.98 \\
\hline
\end{tabular}

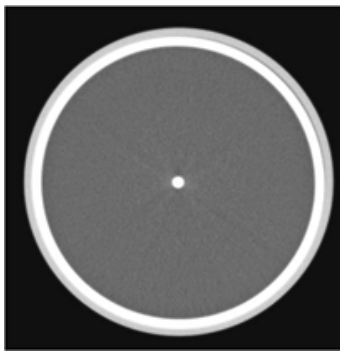

(a) Group A

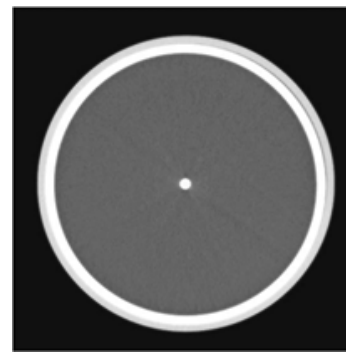

(b) Group B
Figure 3. Analysis of the noise Group A and Group B

\section{2. 영상 화질 분석}

영상의 정량적 분석 결과로 영상 잡음은 $\mathrm{A}$ 군의 우 엽에서 $31.87 \mathrm{HU}$, 좌엽에서 $31.78 \mathrm{HU}$ 로 측정되였으며, $\mathrm{B}$ 군은 우엽에서 $26.6 \mathrm{HU}$, 좌엽에서 $30.42 \mathrm{HU}$ 로 측정 되었다[Table 4].

Table 4. Analysis of the image noise by Groups

\begin{tabular}{ccc}
\hline Group & Group A & Group B \\
\hline Right lobe & 31.87 & 26.6 \\
Left lobe & 31.78 & 30.42 \\
\hline
\end{tabular}

$\mathrm{A}$ 군과 $\mathrm{B}$ 군을 통계적으로 분석한 결과 유의확률은 $0.000(\mathrm{P}<0.05)$ 으로써 $\mathrm{A}$ 군과 $\mathrm{B}$ 군 사이에는 통계적으로 유의한 차이가 있었으며, $\mathrm{A}$ 군이 $\mathrm{B}$ 군보다 영상 잡음이 유의하게 높았다.

\section{3. 임상 영상 평가 분석}

영상의 정성적 평가방법으로 두부 임상 영상 평가 표에 의해 평가한 결과 평균값은 80 점 만점에 $\mathrm{A}$ 군의 관찰자 1 의 점수는 73.17 점, 관찰자 2 의 점수는 74.2 점으로 평가하였으며, $\mathrm{B}$ 군의 관찰자 1 의 점수는 71.77 점, 관찰자 2 의 점수는 72.47 점으로 평가하였다.

$\mathrm{A}$ 군과 $\mathrm{B}$ 군을 통계적으로 분석한 결과 유의확률은 $0.000(\mathrm{P}<0.05)$ 으로써 통계적으로 유의한 차이가 없었으 며, 진단에 적절한 영상을 보였다[Table 5][Fig. 4].

Table 5. Results of clinical evaluation by Groups

\begin{tabular}{ccc}
\hline Score & Group A & Group B \\
\hline Observer 1 & 73.17 & 71.77 \\
Observer 2 & 74.2 & 72.47 \\
\hline
\end{tabular}

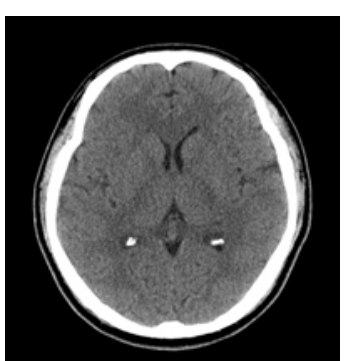

(a) Group A

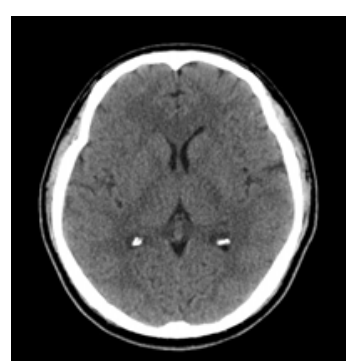

(b) Group B
Figure 4. The Diagnostic evaluation of Group A and Group B

\section{4. 피폭선량 분석}

피폭선량의 분석 결과로 $\mathrm{A}$ 군은 $47.79 \mathrm{mGy}, \mathrm{B}$ 군은 $25.03 \mathrm{mGy}$ 로 측정되였다[Table 6].

Table 6. Results of Radiation dose by Groups

\begin{tabular}{ccc}
\hline Group & Group A & Group B \\
\hline (mGy) & 47.79 & 25.03 \\
\hline
\end{tabular}

$\mathrm{A}$ 군과 $\mathrm{B}$ 군을 통계적으로 분석한 결과 유의확률은 0.000 ( $\mathrm{P}<0.05)$ 으로써 $\mathrm{A}$ 군과 $\mathrm{B}$ 군 사이에는 통계적으로 
유의한 차이가 있었으며, B군이 $\mathrm{A}$ 군에 비해 피폭선량 이 $47.6 \%$ 감소하였다.

이는 건강 검진을 목적으로 하는 두부 CT 검사 시 에 선택적으로 ASIR $50 \%$ 를 적용하여 검사 하면 피폭 선량을 훨씬 더 감소 시킬 수 있다.

\section{IV. 고찰 및 결론}

CT 검사는 영상의학과에서 두부 질환을 진단하는 데 있어서 다른 어떤 검사 방법 보다 우수한 공간 분 해능을 제공하며, 정확하고 양질의 영상을 얻을 수 있 기에 계속적으로 증가되고 있다 ${ }^{[12]}$.건강 검진 검사에 있어 조기 진단을 목적으로 CT 검사가 많이 이용되고 있는 이유는 미세한 병변에 대한 민감도가 높고, 형태 학적인 변화로 부터의 병기 결정 및 주위 구조물과의 관계를 통해 다른 조직의 이상 유무를 잘 확인할 수가 있다. 그러나 CT 검사는 다른 검사에 비해 많은 선량 이 사용되고 있어서 환자 및 일반인들의 관심이 증가 되고 있다. 이에 대부분의 장비회사에서는 선량을 줄 이면서 진단 가치가 있는 영상을 얻기 위하여 계속적 으로 노력하고 있다. 피폭선량을 줄이고 진단 가치가 있는 영상을 유지하기 위하여 ASIR 기법을 적용하여 검사하였다. ASIR 기법은 필터 보정 역투영법과 달리 통계적으로 영상을 반복 재구성하는 방법으로써 저선 량 검사로도 진단적 가치가 있는 영상을 얻을 수 있게 되었다. 즉 영상의 노이즈를 선택적으로 감소시키는 기술로 인해 피폭선량을 감소시키며, 진단적으로 가치 가 있는 화질의 영상을 생성하게 되었다 ${ }^{[13]}$. 또한 반복 재구성 기법은 컴퓨터 처리속도와 소프트웨어의 발전 을 통한 기법으로 기존 검사 보다 더 선량을 줄이면서, 진단적 가치가 있는 영상을 얻을 수 있게 되었다 ${ }^{[14]}$.

A. K. Hara 등은 CT 검사 시에 ASIR를 적용함으로 써 영상 노이즈를 $65 \%$ 까지 감소 시킬 수 있다고 보 고 하였으며, 방사선 피폭선량은 $30 \% \sim 50 \%$ 까지 감소 시킬 수 있다고 보고 하였다. 또한, ASIR 알고리 즘은 비만 환자들을 검사하는데 도움이 된다고 보고 되었다 ${ }^{[13,15]}$.

K. Kalra 등은 흉부 CT 검사 시 ASIR를 적용함으로써 약 $30 \%$ 정도 선량을 감소 시킬 수 있다고 보고 하였다 [14]
ASIR는 $10 \%$ 에서 $100 \%$ 까지 적용할 수가 있으며, $100 \%$ 까지 적용을 하게 되면 노이즈가 너무 적어져 이미지가 인공적인 것 처럼 보이게 된다.

노이즈를 줄이면서 적절한 진단 가치가 있는 영상 을 얻기 위해 대부분의 사용자들은 ASIR $30 \sim 50 \%$ 를 선호하고 있다. 많은 사용자들은 $50 \%$ ASIR 적용이 노이즈를 줄이는 동시에 진단 가치가 있는 영상을 얻 을 수 있는 적절한 균형점이라고 생각하고 있다 ${ }^{[13]}$.

따라서, 본 연구에서는 두부 CT 검사 시 ASIR $50 \%$ 적용하여 검사 하였으며, 팬텀연구와 임상연구를 통하 여 노이즈 및 화질 평가, 피폭선량의 감소에 대하여 알아보고자 하였다.

$\mathrm{CT}$ 노이즈의 경우 팬텀연구에서 ASIR를 적용하지 않은 A군과 ASIR $50 \%$ 를 적용한 B군 사이에는 B군이 $\mathrm{A}$ 군보다 평균적으로 $46.6 \%$ 정도의 노이즈가 감소되 었다. 또한, 임상연구에서 $\mathrm{CT}$ 노이즈는 $\mathrm{A}$ 군과 B군 사 이에 통계적으로 유의한 차이가 있었으며, $\mathrm{A}$ 군이 $\mathrm{B}$ 군 보다 영상 노의즈가 유의하게 높았다.

임상 영상 평가에서 $\mathrm{A}$ 군과 $\mathrm{B}$ 군을 통계적으로 분석 한 결과 통계적으로 유의한 차이가 없었으며, 진단에 적절한 영상을 보였다.

따라서, 두부 CT 검사 시 ASIR $50 \%$ 를 적용하여 검 사하여도 영상의 질에는 부정적인 영향을 주지 않는 다고 볼 수가 있다. 또한, ASIR $50 \%$ 적용하여 검사 함으로써 영상의 질적 저하없이 방사선 피폭선량을 $47.6 \%$ 감소 시킬수 있었다.

본 연구 제한점은 $\mathrm{ASIR}$ 알고리즘이 GE 장비에 국 한 되어 있으며, 건진 환자와 같은 비 질환군을 대상 으로 하였다. 향후에는 질환군을 대상으로 연구 한다 면 다양한 결과가 나타날 수 있을 것으로 생각된다.

결론적으로 두부 CT 검사 시 ASIR $50 \%$ 적용하여 검사함으로써 영상의 질적 저하 없이 방사선 피폭선 량을 $47.6 \%$ 감소 시킬수 있었다.

앞으로 여러 임상 부위에 ASIR가 적용이 된다면 훨 씬 더 적은 선량으로도 검사가 가능할 것으로 생각된 다. 또한 검사 시에 검사자가 판단하는데 있어 긍정적 인 요인이 될 것으로 생각된다. 


\section{Reference}

[1] Mulken TH, Bellinck P, Baeyaert M, "Use of an auto- matic exposure control mechanism for dose optimization in mul ti detector row CT examinations: clinical evaluation,” Radiology, Vol. 237, No. 1, pp.213-223, 2005.

[2] Seibert, JA, Barnes, GT, Gould, RG, "Specification, Acceptance testing and quality control of diagnostic X-ray imaging equipment," Medical physics monograph, Vol. 20, pp.899-936, 1991.

[3] Lee $\mathrm{CH}$, Goo M, Ye HJ, "Radiation dose modulation tech niques in the multi detector CT era: from basics to practice," RadioGraphics, Vol. 28, No. 2, pp.1451-1459, 2008.

[4] Smith AB, Dillon WP, Lau BC, "Radiation dose reduction strategy for CT protocols:successful implementation in neuro radi ology section," Radiology, Vol. 247, No. 2, pp.499-506, 2008.

[5] Silva AC, Lawder HJ, Hara A, "Innovations in CT Dose Reduction Strategy: Application of the Adaptive St atistical Iterative Reconstruction Algorithm," AJR, Vol. 194, No. 1, pp.191-199, 2010.

[6] International Commission on Radiological Protection, "Managing Patient Dose in Computed tomography, in Ann ICRP 2000(Per gamon Oxford, 2000)," ICRP Publication 87, Vol. 30, No. 4, 2000 .

[7] National Radiological Protection Board, "Radiation Exposure of the UK Population from Medical and Dental X-Ray Examinatio ns(NRPB Chiton, Didcot, Oxon UK, 2002)," NRPB_W4, 2002.

[8] Ko YH, Kwon DC, Kim KK, "Textbook of Computed Tomography," Chung--ku Publishing co, 2009.

[9] ICRP Publication 87, "Managing Patient Dose in Computed Tomography," Elsevier Ltd, The boulevard, Langford Lane, Kidling ton, Oxford, 2004.

[10] ICRP Publication 102, "Managing Patient Dose in Multi-Detector Computed Tomography," Elsevier Ltd, The boulevard, Langford Lane, Kidling ton, Oxford, 2007.

[11] Ko SJ, Kang SS, "Optimization of Exposure Parameters in Brain Computed Tomography," Journal of Korean Society of Radiological science, Vol.33, No.4, pp.355-362, 2010.

[12] Diederich S, Wormanns D, Heindel W. "Lung Cancer screening with low-dose CT," Europen Journal of Radiology, Vol. 45, No. 2, pp.2-7, 2003.

[13] Hara, AK, Paden, RG, Silva, AC, "Iterative Reconstru ction Technique for Reducing Body Radiation Dose at CT, feasi bility study," AJR, Vol. 193, No. 3, pp.764-771, 2009.
[14] Kalra K, Subba R, Jiang H, "Radiation dose reduction with chest Computed Tomography using Adaptive Statistical Iter ative Reconstruction technique, Initial experience," J Comput Assi st Tomogr, Vol. 34, No. 3, pp.40-45, 2010.

[15] Hara, AK, , Silva AC, Lawder, HJ, "Adaptive Statistic al Iterative Reconstruction algorithm," AJR, Vol. 194, No. 3, pp.191-199, 2010. 